\title{
Orofacial pain and the International Year
}

\author{
As dores orofaciais e o Ano Mundial
}

Dear readers,

We are in the International Year against Orofacial Pain, undoubtedly an area with the most pain-related diagnoses, because it has more than 300 causes. The prevalence is between $10 \%$ and $30 \%$ of general population and, if this were not enough, it includes highly complex and important anatomic and histological structures for social living and survival, which calls for several specialists such as dental surgeons, ENT specialists, ophthalmologists, speech therapists, in addition to other professionals who are part of interdisciplinary pain teams ${ }^{1}$.

In spite of this relevance, academic curricula to qualify health professionals in pain are still poor still during graduation, and Dentistry is not different in this aspect. This year, for the first time, we have an optional discipline contemplating the subject in the Dentistry School, University of São Paulo, resulting from the vision of Prof. Victor Arana Chavez about this need. We wish that such initiative becomes mandatory and is spread to all universities.

Traditionally, Revista Dor reserves its space to Orofacial Pain, particularly to temporomandibular disorders (TMD), which are contemplated in two articles of this edition. This is a major group of diseases of the masticatory, muscular, articular systems or mixed, which are only second in prevalence to dental-alveolar pain. They may affect different age groups and are comorbidities of other diagnoses such as trigeminal neuralgia, pulpitis, migraine and fibromyalgia ${ }^{2,3}$. So, they need careful evaluation for thorough diagnosis and choice of therapies with scientific evidence.

Among treatments, there are invasive and non-invasive procedures including bite plates, acupuncture, physiotherapy, drugs, cognitivebehavioral therapy, surgeries and viscosupplementation. When adequately indicated, treatments are effective and I highlight a retrospective study on viscosupplementation, important technique to treat internal temporomandibular joint (TMJ) disorders ${ }^{4}$.

Psychological and psychiatric comorbidities are also part of the set of morbidities associated to facial pain and caregivers should pay special attention to sufferers. Atypical facial pain, for example, has a high prevalence of associated emotional symptoms which have to be addressed ${ }^{5}$. Patients with trigeminal neuralgia are frequently isolated and end up with depression. And common tooth pain, when referred, may take months to be diagnosed and lead patients to total withdrawal from all their family, professional and leisure activities, even in such a short period of time.

It also has to be stressed the important role of pain in the elderly in a current aging society which looks for quality of life in any age group. Elderly and children are special groups needing adequate care to their clinical condition and sometimes treatments such as acupuncture may help relieving symptoms with few adverse effects.

So, enjoy your reading and let's hope that many scientific and academic advances occur in the Orofacial Pain universe during this International Year.

Best regards!

Silvia Regina Dowgan Tesseroli de Siqueira

Executive Editor

\section{REFERENCES}

1. Teixeira MJ, Siqueira SRDT, Kosminsky M, Monteiro AA. Epidemiologia da dor. In: Teixeira MJ e Siqueira JTT. Dores orofaciais: diagnóstico e tratamento. São Paulo: Artes Médicas; 2012. 46-59p.

2. de Siqueira SR, da Nóbrega JC, Teixeira MJ, de Siqueira JT. Masticatory problems after balloon compression for trigeminal neuralgia: a longitudinal study. J Oral Rehabil. 2007;34(2):88-96. 3. Bernstein JA, Fox RW, Martin VT, Lockey RF. Headache and facial pain: differential diagnosis and treatment. J Allergy Clin Immunol Pract. 2013;1(3):242-51.

4. Long X, Chen G, Cheng AH, Cheng Y, Deng M, Cai H, et al. A randomized controlled trial of superior and inferior temporomandibular joint space injection with hyaluronic acid in treatment of anterior disc displacement without reduction. J Oral Maxillofac Surg. 2009;67(2):357-61.

5. Madland G, Feinmann C. Chronic facial pain: a multidisciplinary problem. J Neurol Neurosurg Psychiatry. 2001;71(6):716-9. 